\section{CEREBRAL DYSPEPSIA.}

\author{
BY J O H N S. MAIN, M.D. (Glasg.), C.M., \\ Chorlton Union Hospitals, Withington, Manchester.
}

AxoyGsT the common complaints met with in practice, perhaps none are more common than the various forms of dyspepsia. That these are on the increase at the present day, few, I think, will gainsay; nor can this be wondered at, when we bear in mind the "high pressure" system under which many of us live, and which the "spirit of the times" almost necessitates. More than ever, is the present age an aspiring one; and so the truth of the poetical quotation from Beattie-

"Ah! who can tell how hard it is to climb

"The steep, where Fame's proud temple stands afar"-

is becoming more and more felt-no doubt in more senses than the poet had in view when he wrote this.

That people differ, in the amount of steady and continuous exertion to which they can put their mental faculties, is as much a truism as that the amount of muscular effort capable of being put forth by different individuals varies; and so, as in the latter case, a person trying to put forth an equivalent amount of muscular effort to his superior in muscular development, can only do so at the expense of much labour and pain, with subsequent muscular exhaustion, and fatigue; and, moreover, cannot continue the same for any length of time; so in the former, an equivalent amount of mental effort can only be put forth at an increased amount of cerebral exertion, over and above what the brain is normally certified for, so to speak. This, acting upon the "reserve fund" of cerebral activity, may not at first be felt to do any or much harm. Nay, it is possible that, in some cases, the brain may accustom itself to it, and grow in its power of withstanding fatigue pari passu; but this is, undoubtedly, by no means generally.the case : for, just as surely as making an increased muscular effort, by the power alcoholic stimulants have to call forth the "reserve fund" of the nervous system, is followed in the long run by collapse, and a total loss of even this power; so surely, in the majority of cases, will the extra calling forth of the cerebral powers, by the stimulus of the will, lead to a collapse in that quarter, with which other quarters sympathise. It is to this " extra calling forth of the cerebral powers" that I have applied the term " high pressure system", under which we live.

And now to the point I have more particularly in view, in introducing this subject in connection with dyspepsia; and offering to add a new form to the already many forms of this disease-a form to which I have given the name of "cerebral". To the close sympathy that exists between the cerebrum and the stomach, I need not refer. This is amply testified by the vomiting which generally follows injury to its substance, and by the vomiting of seasickness, etc., which is no doubt due to its functional disorder. Again, a disturbance (functional) of the cerebrum, through the passions, grief, fear, etc., also acts powerfully on the stomach. Thus, a sudden arrest of appetite and digestion by the receival of a piece of bad news-the stomach sympathising with the brain in this way-is a fact too well known, as is also the quotation from Shakespeare bearing on this point, viz. :

\section{"Read over that, and after that \\ And then to breakfast,}

With what appetite you have."

But, perhaps, of all conditions acting on the brain in this manner, and through the brain on the stomach, no one is more injurious, or more jarring to the cerebral elements, than uncertainty, and the worry caused by the same, more particularly in preternaturally irritable snbjects. On this point, the poet Mallet has well remarked:

$$
\text { "Uncertainty! }
$$

Fell demon of our fears ! The human soul

That can support despair, supports not thee."

In fact, it is in connection with this same worry that the form of dyspepsia I have at present under consideration most frequently occurs. The mind, in such cases, preys upon itself; the cerebral elements seem to get jarred and out of gear; and with this condition the stomach sympathises. But, in addition to worrs, the habitual practice of calling into action the "reserve fund" of the cerebrum, as already mentioned, will bring about the same consequences-namely, cerebral fatigue and exhaustion, indicated chiefly by preternatural irritability; this condition, sooner or later, telling npon the digestive organs. Having said this, it is almost unnecessary to add, that such cases are most commonly met with amongst those who are engaged in the hottest part of the "battle of life", or "struggle for existence"; and, again, amongst these, chiefly those whose business or profession leads to much anxiety, uncertainty, or over-stretching of the mental powers.

Iastly, I would remark that, in over-aspiring, over-ambitious natures "hope deferred" may bring about the same results; or, according to the biblical expression, "it maketh the heart sick." My attention has been drawn to several cases of dyspepsian connected with one or other of these conditions; and what made me more strong in my view of these cases being cerebral, and not stomachic at all in their origin, was their obstinacy under all forms of ordinary treatment. Latterly, I have found that the only treatment capable of doing these cases any permanent good, is a change, in the wide sense of the term-a relaxation from business or study; and, as regards medicines, not such as are meant to act on the stomach directly, but those meant to act on the cerebrum. Amongst these, I have found the most useful to be bromide of ammonium, or bromide of potassium--preferably the former-given in a sufficient dose at bedtime, to secure a good night's sleep, this being often very indifferent, and so tending to complicate the case; and, combined with this, to be taken three or four times during the day, such medicines as are known to have a building-up effect on the nervous system. Amongst these, the most useful are phosphorus, or the hypophosphites, and cod-liver oil. Arsenic and quinine are often also useful, and a generous diet is always indicated. Unless the stomach has passed into a state of disease (which it may do, if overtasked when in this weakened state), any of these medicines are gcnerally well borne. It will be well to bear in mind, however, that if the mucous membrane of the stomach be in a state of irritation, quinine, arsenic, phosphorus, the hypophosphites, and sometimes even codliver oil, are inadmissible.

In conclusion, I would remark that, so far as my experience goes in the treatment of dyspepsia, in the broad sense of the term, I am inclined to think that it is rare to find only one of the conditions requisite to a healthy digestion at fault; and that, consequently, in order to make a successful cure, it is incumbent on us to inquire into all the circumstances of the case, and base the treatment accordingly. The cerebral element, if it be not the fons et origo mali, will often be found to complicate these cases, and to require treatment per se. Much has been written about dyspepsia; but perhaps, after all, in no class of cases is it more difficult to come to an accurate diagnosis.

\section{ON THE THERAPEUTIC VALUE OF SULPHUROUS ACID IN SCARLATINA MALIGNA. \\ Br KEITH NORMAN MACDONALD, M.D., F.R.C.P.Edin., L.R.C.P.Lond.}

THE prevalence of scarlet fever of a more or less malignant type in different parts of the United Kingdom at the present time, induces me to draw attention to the therapeutic value of sulphurous acid in the treatment of that disease, and to comment upon the danger attendant upon an expectant plan of treatment, or of trusting to the use of stimulants, and nourishment only-which can seldom be administered-or any such half measures.

Every practical physician knows very well the inutility of the majority of the drugs with which we are acquainted, and which are ordinarily employed in combating this terrible scourge, and many are led, after repeated failures, to lose confidence in all our most approved measures.

I confess to having had some such notions until I began to use the sulphurous acid, and this was suggested to me on observing white patches at the back of the throat in some cases where there was a well marked scarlatina rash, in fact, in some of the severest forms of the anginose variety.

Some years ago the late Dr. James Dewar of Kirkaldy, strongly recommended the use of sulphurous acid spray in diphtheria and scarlet fever, and since then, I believe, its utility in these diseases has been firmly established.

Whatever pathological difference may exist between malignant scarlet fever and diphtheria, there can be no doubt of a certain similarity of action common to both, viz., blood-poisoning in its most acute and rapidly fatal form. Now, as sulphurous acid is known to destroy all animal vegetable organisms, and it is one of the most convenient agents for administration in such cases, I do not hesitate in affirming that, when properly applied, both locally and internally, it is by far the most efficacious remedy we possess. In order, however, to ensure success, it is necessary that its application should be both continuously and intelligently employed and when so used, the 